\title{
Educação Infantil do Campo: trajetória das políticas educacionais e suas implicações no cotidiano das instituições escolares
}

\author{
Childhood Education in Rural Areas: trajectory of public policies and \\ implications in the daily routine of educational institutions \\ Leomárcia Caffé de Oliveira Uzêda \\ Elizabete Pereira Barbosa
}

\begin{abstract}
Resumo: Este artigo faz uma análise das políticas educacionais para Educação do Campo no Brasil e do processo de implementação dessas políticas na Educação Infantil do Campo estabelecendo uma interface entre o itinerário legislativo e os possíveis desdobramentos no cotidiano das instituições que acolhem crianças de zero a cinco anos, da zona rural. Trata-se de um recorte da pesquisa "Educação infantil na zona rural: caracterização e análise do cenário de implementação das políticas de educação do campo no município de Feira de Santana", realizada pelo Centro de Estudos e Documentação em Educação da Universidade Estadual de Feira de Santana. Para compreender a realidade da Educação da Infantil na zona rural foi preciso contextualizar o movimento das políticas públicas e reconhecer o ordenamento jurídico como um dos instrumentos viáveis de luta. O presente trabalho baseia-se em análise bibliográfica e documental dos marcos legislativos para delimitar a responsabilidades das esferas municipal, estadual e federal com a qualidade da oferta e permanência das crianças na escola (BRASIL, 1988; BRASIL, 1996; BRASIL, 1998; BRASIL, 2002; BRASIL, 2009, BRASIL, 2010). Os resultados da pesquisa indicam que há avanços em direção ao cumprimento das normas estabelecidas no ordenamento jurídico nacional, mas que ainda há um fosso em direção ao alcance de uma Educação Infantil do Campo de qualidade respeitando as especificidades socioculturais, as necessidades formativas e educacionais das crianças.
\end{abstract}

Palavras-chave: Educação do Campo; Ordenamento Jurídico; Políticas Educacionais; Educação Infantil do Campo.

Abstract: This paper analyzes the public policies for Rural Education in Brazil and the implementing process of these policies in Childhood Education by establishing an interface between the legislative itinerary and the possible impacts in the daily life of institutions that assist children from zero to five years old. This study is an excerpt from the research "Childhood education in rural areas: characterization and analysis of the scenario for implementation of rural educational policies in the municipality of Feira de Santana", carried out by the Center for Studies and Documentation in Education at the Feira de Santana State University. In order to comprehend the surroundings of Childhood Education in Rural areas, it was necessary to contextualize the changes in public policies and acknowledge the judicial order as a viable instrument towards fighting for social rights. The present work is based on bibliographic and documentary analysis of the legislative marks to delimit the responsibilities of the municipal, state and federal spheres regarding the enrollment capacity and the children's permanence in school. (BRASIL, 1988; BRASIL, 1996; BRASIL, 1998; BRASIL, 2002; BRASIL, 2009, BRASIL, 2010). The research results indicate that there are improvements concerning the fulfillment of norms established in the national judicial order, but there is still a gap 
towards the achievement of quality childhood education in regard to the sociocultural specificities, as well as, the children's formative and educational needs.

Keywords: Rural Education; Judicial Order; Educational Policy; Childhood Education.

\section{Introdução}

O propósito deste trabalho é apresentar uma análise das políticas para Educação do Campo (EC) a nível nacional estabelecendo uma interface entre o itinerário legislativo e seus desdobramentos no cotidiano de crianças que vivenciam a Educação Infantil (EI) na Zona rural.

Abordar a temática infância no contexto educacional é uma tarefa complexa, uma vez que envolve outras dimensões, para além da dicotomia cuidar e educar, das políticas de formação destinadas aos profissionais, dos desafios e dilemas existentes na docência nesta etapa de ensino, entre outras questões. Para compreender a infância e o processo de escolarização no território rural é necessário considerar as singularidades e especificidades próprias deste grupo de ensino.

Trata-se de um tema ainda pouco investigado cuja produção na literatura ainda é escassa, remetendo-nos a necessidade não só de discutir o mesmo, mas apontar proposições para as crianças e infância que povoam a Educação Infantil do Campo (EIC). Diante disso, refletir sobre itinerário legislativo e a implementação de políticas para a educação das crianças do Campo é algo premente. A discussão gira em torno da defesa de que a educação escolar é obrigação do Estado, direito das crianças e que precisa contribuir para o desenvolvimento, aprendizagem das diversas linguagens, valorização dos saberes e culturas das infâncias do campo.

Quanto à concepção de infância, no presente texto, concebe-se a mesma enquanto categoria social, histórica e geracional. A criança, aquela que se assenta na infância, é compreendida como sujeito histórico, social, de direitos e produtor de cultura. (KRAMER, 1996; KUHLMANN Jr, 2000; LAJOLO, 2009; BARBOSA, 2015; UZÊDA, 2013).

A Educação do Campo é compreendida como uma política educacional de lógica sociocultural, sendo específica e voltada para os sujeitos do campo, 
devendo dialogar, também, com as demandas da educação para a infância em seus contextos institucionais. O "campo" é compreendido como um espaço de produção, criação e vida com relação direta ou indireta com a cidade, como já anunciado pelo Movimento de Articulação por uma Educação do Campo. (ARROYO, CALDART, MOLINA, 2008; MUNARIM, 2008; CALDART, 2012; UZÊDA, 2013).

A Educação Infantil do Campo é compreendida como um movimento em construção, política pública que vivencia a interface entre conhecimentos, conteúdos, objetivos, entre outros aspectos mais gerais e específicos da Educação Infantil com políticas públicas voltadas para Educação do Campo. (SILVA, PASUCH, SILVA, 2012; BARBOSA, GEHLEN, FERNANDES, 2012)

O ordenamento jurídico é concebido aqui como instrumento viável de luta, como um caminho para desvelar os impasses, as disputas e os marcos na constituição da educação. Do ponto de vista social impulsiona o cumprimento de obrigações e, portanto, a conquista de direitos. (BARBOSA, 2015).

No presente texto para compreender quais as implicações das políticas para EIC no cotidiano de instituições escolares em zonas rurais parte-se de uma análise bibliográfica e documental que aponta a trajetória do ordenamento jurídico e documentos oficiais sobre a Educação do Campo e Educação Infantil do Campo.

Toma-se como marco inicial, a Constituição de 1988 que declara no art. 205 "educação é direito de todos, do estado e da família", imprimindo demandas indispensáveis para os sistemas de educação e para sociedade civil que passa a ter garantias legais de acesso à educação.

No mesmo sentido de ampliação de direito a educação, a Lei de Diretrizes e Bases da Educação Nacional, LDB 9.394/96, estabelece no Art. 28, a necessidade de adaptações na oferta de educação básica para a população rural, considerando os conteúdos, metodologias, organização escolar própria, adequação do calendário e a organização do trabalho pedagógico à natureza do trabalho na zona rural. Tais marcos legais incidiram na elaboração e implementação de outros documentos que, timidamente, tocaram em pontos significativos sobre a EIC. 
O texto está organizado em duas seções: na primeira, abordamos a trajetória da Educação do Campo a partir de ordenamento jurídico já apresentando a interface com EIC; na segunda seção, analisamos os desdobramentos e implicações de tais políticas no cotidiano das crianças que habitam a zona rural e frequentam instituições de Educação Infantil em tais territórios.

Compreende-se e defende-se que políticas públicas sejam criadas e implementadas com a intenção de contribuir com a vida das infâncias do campo, que além do direito a aprendizagem de qualidade conforme estabelece a legislação, carecem de garantias e condições de acesso e continuidade em seus territórios rurais.

\section{Educação Infantil do Campo: a trajetória de um ordenamento jurídico}

A Educação do Campo vem conquistando através de muitas lutas o seu espaço no cenário educacional brasileiro, mas especificamente nas décadas finais do Século XX o movimento em prol de uma Educação do Campo tem ampliado o debate voltado para as realidades e cultura dos povos do campo. Essa discussão ganhou maior visibilidade, conquistou avanços qualitativos evidenciando a necessidade e importância de considerar as especificidades da educação em territórios rurais.

Fruto das lutas dos movimentos e organizações sociais dos trabalhadores rurais, a Educação do Campo imprime uma nova concepção no que concerne ao campo e aquele que o habita. De acordo com Souza (2008, p.1096)

[...] O marco da inserção da educação do campo na agenda política e na política educacional pode ser indicado a partir da LDB 9394/96, ao afirmar, em seu artigo 28 , a possibilidade de adequação curricular e metodologias apropriadas ao meio rural; flexibilizar a organização escolar, com adequação do calendário escolar. Na sequência, houve a aprovação das Diretrizes Operacionais para a Educação Básica nas Escolas do Campo.

Se considerarmos as contendas em volta da Educação do Campo, veremos que é um conceito "relativamente recente", e que segundo Caldart (2009, p.39) nasce "como crítica à realidade da educação brasileira, particularmente à situação educacional do povo brasileiro que trabalha e vive 
no/do campo". (CALDART, p.39). A autora ainda destaca que a Educação do Campo "surgiu como contraponto de práticas, construção de alternativas, de políticas, ou seja, como crítica projetiva de transformações". (CALDART, p.39).

A EC emerge das lutas dos trabalhadores e trabalhadoras rurais que passaram a reivindicar seus direitos e por um protagonismo que lhe fora negado, invisibilizado por décadas. Os movimentos sociais juntamente com sindicatos rurais vêm se organizando em defesa do direito à terra e à educação dos povos do campo, que até então não tomou o espaço educacional de maior visibilidade. A terminologia política "Educação do Campo" insurge para romper com os modelos existentes de educação, nos quais os sujeitos do campo em sua totalidade são vistos como os atrasados, recebendo como protótipos educacionais um modelo urbanocêntrico.

Se na zona urbana, identifica-se o colapso dos serviços públicos destinados à população, na zona rural não é diferente, agravando-se em determinadas dimensões os mesmos aspectos, uma vez que se constitui no local onde se intensifica bolsões de pobreza, miséria, disparidades e a exclusão social, ou seja,

[...] este cenário atravessa a história de cinco séculos a serviço do projeto de desenvolvimento brasileiro. E dentro dele a história de subordinação e luta vai sendo construída e pouco esclarecida. [...] É no início do século XX que quando o rural busca o urbano, desejando os louros do que se chamava desenvolvimento, que a construção desse hiato urbano/rural se estabelece. Ironicamente, são os que migram, os que se deslocam que chamam relativa atenção para a condição do rural que deixaram para trás. (CAVALCANTE, 2007, p.24).

O excerto ilustra o panorama de desigualdades e condições de vida que historicamente traduz o modo de vida rural no país. $E$, no que tange o âmbito educacional, ainda são muitos os problemas enfrentados na área rural, a exemplo de transposição da realidade urbanocêntrica para as escolas rurais, dificuldades de acesso e permanência nas escolas, desvalorização da cultural local, currículo escolar vivenciado e reproduzido a partir da realidade da cidade, em detrimento de uma supervalorização da vida urbana, entre outras questões.

A Educação do Campo integra a ação por educação ao conjunto das lutas pela mudança da qualidade de vida dos povos campesinos, se estabelecendo 
em uma alternativa de caráter sociopolítico, cultural e pedagógico que procura pelo meio de políticas públicas o direito a uma escola no campo e também do campo, que pondere os conhecimentos de educação, a identidade e a realidade dos povos que compõe o território rural brasileiro (CAVALCANTE, 2010; ARROYO, CALDART, MOLINA, 2008; UZÊDA, 2013; CAVALCANTE, BARBOSA, REHEM, UZÊDA, 2014).

As ações políticas e contínuas dos movimentos sociais por uma educação do e no campo, procuram contribuir na constituição da identidade dos múltiplos sujeitos que vivem este campo. Nesse sentido, as escolas do campo têm um papel importante de fortalecer o sentimento de pertença desses sujeitos e de articular os conhecimentos produzidos historicamente na sociedade com os construídos histórica e culturalmente pelas comunidades das quais estes sujeitos fazem parte.

Entre movimentos específicos em prol da Educação do Campo, encontrase a busca pela qualidade da Educação Infantil nos territórios rurais. Quem são as crianças e infâncias que habitam o campo, os mais variados territórios rurais? Que escolas estão sendo forjadas para elas? A EIC se constitui como um movimento recente, que vem ganhando espaço em cenários públicos e se apresenta como uma necessidade e reivindicação dos povos do campo, que engajados nos movimentos sociais anseiam uma educação de qualidade para os seus filhos logo na primeira infância. A pauta por uma EIC de qualidade precisa ser considerada, respeitada.

A expressão Educação Infantil do Campo será apresentada no decorrer do texto, por opção política, mas também porque,

[...] Uma educação infantil do campo de qualidade... necessita considerar novas questões, construindo um cenário de relações positivas da criança com suas origens e lugares de vida, consigo mesma e com o seu grupo de referência, valorizando suas experiências cotidianas. [...] Oferecer uma educação infantil que não seja profundamente comprometida com a valorização dos saberes dos povos do campo significa: colocar as crianças do campo em posições de inferioridade; reiterar os estereótipos, preconceitos e as concepções do senso comum sobre o homem/mulher do campo; abrir mão de usar do processo pedagógico para o questionamento, no cotidiano com as 
crianças, dessas imagens e estereótipos. (SILVA, PASUCH, 2010, p.4)

Para compreender a realidade da educação das crianças pequenas na zona rural, é preciso contextualizar o movimento de políticas públicas e reconhecer o ordenamento jurídico como um instrumento viável de luta. Os pressupostos para análise nesse texto consideram que a Educação Infantil é a primeira etapa da Educação Básica e precisa assegurar o desenvolvimento pleno das crianças de zero a cinco anos de idade. De acordo com a Lei de Diretrizes e Bases da Educação Nacional, LDB nº 9.394, de 20 de dezembro de 1996, no seu Art. 29:

[...] A educação infantil, primeira etapa da educação básica, tem como finalidade o desenvolvimento integral da criança até seis anos de idade, em seus aspectos físico, psicológico, intelectual e social, complementando a ação da família e da comunidade. (BRASIL, 1996)

Como incita Barbosa e Almeida (2019) é digno de nota aqui delimitar a responsabilidades das esferas municipal, estadual e federal com a qualidade da oferta e permanência das crianças na escola. Neste caso, a Educação Infantil é responsabilidade dos munícipios que em conformidade com a Lei 9.394/96 estabelece no Art.11 que:

[...] Os Municípios incumbir-se-ão de: V-oferecer a educação infantil em creches e pré-escolas, e, com prioridade, o ensino fundamental, permitida a atuação em outros níveis de ensino somente quando estiverem atendidas plenamente as necessidades de sua área de competência e com recursos acima dos percentuais mínimos vinculados pela Constituição Federal à manutenção e desenvolvimento do ensino (BRASIL, 1996).

Atentando-se ao ordenamento jurídico, as ações da escola, família e comunidade são indissociáveis para que haja uma educação de qualidade no território rural. A mesma lei estabelece no Art. 28, a necessidade de adaptações na oferta de educação básica para a população rural e determina que os sistemas de ensino promovam as adaptações necessárias à sua adequação às peculiaridades da vida rural e de cada região. $O$ artigo da lei assevera o dever dos estabelecimentos de ensino em assegurar tais adaptações e dispõe que: 
I. conteúdos curriculares e metodologias apropriadas às reais necessidades e interesses dos alunos da zona rural;

II. organização escolar própria, incluindo adequação do calendário escolar às fases do ciclo agrícola e às condições climáticas;

III. adequação à natureza do trabalho na zona rural. (BRASIL, 1996)

Considerando o artigo supracitado, está prescrito em lei, que a Educação do Campo é necessária, e para que ela aconteça com qualidade os estabelecimentos de ensino devem fazer as adaptações indispensáveis. Assim, deve ser considerada com todas as suas especificidades, enfatizando a importância da permanência na escola e as aulas precisam ser ministradas despertando nos alunos da zona rural o prazer e o encanto em aprender.

Embora os movimentos voltados para uma Educação do Campo de qualidade e que reivindicam escolas no/do campo que atendam suas reais necessidades, ainda existe um caminho longo a se avançar. E quando nos reportamos à Educação Infantil em zonas rurais, há um agravamento, dada a invisibilidade que a infância ocupa nesses espaços historicamente. De acordo com Silva; Pasuch, Silva (2012, p.51),

[...] não se pode oferecer à criança do campo uma educação voltada para uma criança abstrata, sem contexto. Esse contexto é o campo significativo para seu desenvolvimento e precisa dialogar com as formas de educá-la em espaços públicos e coletivos. Daí falar em "Educação Infantil do Campo".

A Educação Infantil é um direito das crianças independentemente de serem dos territórios rurais. Mas, em sendo, é preciso garantir uma educação de qualidade a infância do campo, com o intuito, entre outros, de dar sentindo as experiências vividas e que fazem parte do seu meio social e cultural. Uma EIC que valorize e potencialize as crianças mirando sua formação humana e seu desenvolvimento irrestrito, avigorando a ideia de que são produtores de conhecimento e cultura.

No que se refere ao campo educacional para as crianças que habitam o território rural, o acesso e permanência na EIC permanece um desafio constante. Não só o ingresso, mas o atendimento, cuidado e educação da infância nesses espaços seguem também, na atual circunstância política-social-econômica do 
país e do mundo, o imperativo de ressignificação dos conceitos de uma educação, currículo, gestão escolar, práticas pedagógicas, aspectos infraestruturais, entre outras dimensões, que envolvem o cotidiano infantil nas escolas rurais. (CAVALCANTE, BARBOSA, REHEM, UZÊDA, 2014; SILVA; PASUCH, SILVA, 2012).

No âmago desse desafio fica a importância de fazer o debate sobre as condições materiais para a oferta e permanência na EIC com uma visão ainda mais criteriosa e de investigações que considerem concepções envolvidas no seu processo de constituição, já que é um movimento em construção, a saber: visões de infância, criança, docência, Educação do Campo e Educação Infantil que acendem ponderações e a precisão de abranger sua complexidade. (SILVA, PASUCH, 2010).

A despeito da apreciação acerca dos avanços alcançados ao longo da trajetória das políticas no Brasil, no que diz respeito a EIC, também é imprescindível maior investimento em políticas que considerem as crianças do campo, assim como outras ações unidas diretamente aos sujeitos que vivem o dia a dia escolar nos territórios rurais. A EIC se estabelece como um movimento recente, que vem ganhando espaço em cenários públicos como uma necessidade e exigência dos sujeitos do campo, que almejam uma educação de qualidade desde a primeira infância.

Quanto a El, no Brasil, observa-se no itinerário legislativo avanços no campo da proteção da infância e na criação de leis, após a Constituição de 1988, que amparam as mesmas, a exemplo do Estatuto da Criança e Adolescente, Lei No 8.069/1990 (BRASIL, 1990), a Lei de Diretrizes e Bases da Educação Nacional, Lei no 9.394/96 (BRASIL, 1996), Os Referenciais Curriculares Nacionais da Educação Infantil (BRASIL, 1998), Parâmetros nacionais de qualidade para a educação infantil (BRASIL, 2006), Parâmetros básicos de infraestrutura para instituições de educação infantil (BRASIL, 2006a), Diretrizes Curriculares Nacionais para Educação Infantil (BRASIL, 2009) que apontam em seus textos melhorias e avanços no âmbito geral da educação para as crianças e infâncias brasileiras. Entretanto, não dão conta, ainda, de reservar o debate e assegurar especificidades das crianças que habitam o rural. É a partir da década 
de 2000, que a discussão da Educação Infantil do Campo (EIC), vai se ampliar e ganhar certo espaço no cenário das políticas públicas educacionais, ainda que timidamente.

Avaliando ações implementadas no contexto das políticas educacionais para EC encontramos, por exemplo, a aprovação pelo Ministério da Educação e Cultura (MEC) do Parecer 36/2001 e da Resolução 01/2002 através do Conselho Nacional de Educação que instituiu as Diretrizes Operacionais para Educação Básica das Escolas do Campo, pleiteadas a partir da I Conferência Nacional sobre Educação do Campo. Ainda em 2002 foi elaborado o Parecer CNE/CEB 21/2002 que solicita análise da possibilidade de reconhecimento nacional das Casas Familiares Rurais.

Um elemento expressivo para infância do campo são Diretrizes Operacionais para a Educação Básica nas Escolas do Campo - DOEBEC, (Resolução CNE/CEB 1, de 3 de abril de 2002) que reconhecem o modo próprio de vida social e o de utilização do espaço do campo como fundamentais para a construção da identidade da população rural. As Diretrizes no seu art. $2^{\circ}$ indica que:

[...] com base na legislação educacional, constituem um conjunto de princípios e de procedimentos que visam adequar o projeto institucional das escolas do campo à Diretrizes Curriculares Nacionais para a Educação Infantil, o Ensino Fundamental e Médio, Educação de Jovens e Adultos, a Educação Especial, a Educação Indígena, a Educação Profissional de Nível Técnico e a Formação de Professores em Nível Médio na modalidade Normal (BRASIL, 2002).

Trata-se de um documento importante para a Educação do Campo, pois se ocupa de orientações e da organização das escolas do campo. Neste mesmo ano, a Resolução $n^{\circ}$ 02, constituiu diretrizes complementares, normas e princípios para o desenvolvimento de políticas públicas de atendimento da Educação Básica do Campo.

Nos anos seguintes, outros avanços podem ser evidenciados, como em 2003, quando foi criado um Grupo Permanente de Trabalho (GPT); em 2004 foi implantada a Coordenadoria Geral da Educação do Campo na esfera da SECAD-MEC que promovia discussões, debates e eventos voltados para a 
temática, a saber: a II Conferência nacional por uma educação do Campo, I, II e III Encontro nacional de Educação do campo ocorridos na sequência em 2006, 2008 e 2010. Ainda no ano de 2006 foi elaborado o Parecer CNE/CEB 1/2006 (BRASIL, 2006b) que aborda sobre dias letivos para aplicação da Pedagogia da Alternância nos Centros Familiares por Formação da Alternância (CEFFA), sendo que nos anos seguintes foram criados o Parecer CNE/CEB 23/2007 (BRASIL, 2007) relativo à Consulta referente às Orientações para o Atendimento da Educação do Campo e a Resolução CNE/CEB 03/2008 que estabelece Diretrizes Complementares Normas e princípios de políticas públicas para o atendimento da Educação Básica do Campo.

A despeito das aquisições e melhorias das políticas públicas na educação a nível geral, e especificamente na Educação do Campo, no que tange as crianças que vivem no território rural existiu certa supressão no processo de organização e elaboração das leis, de programas, de campanhas educacionais, por exemplo. Ainda sobre a Educação Infantil do Campo o Parecer das DOEBEC apresenta mais dois artigos, que pontualmente citam esta etapa de ensino nos territórios rurais, a saber:

[...] Art.6 $6^{\circ}$ O Poder Público, no cumprimento das suas responsabilidades com o atendimento escolar e à luz da diretriz legal do regime de colaboração entre a União, os Estados, o Distrito Federal e os Municípios, proporcionará Educação Infantil e Ensino Fundamental nas comunidades rurais, inclusive para aqueles que não o concluíram na idade prevista cabendo em especial aos Estados garantir as condições necessárias para o acesso ao Ensino Médio e à Educação Profissional de Nível Técnico. (BRASIL, 2002, p. 22)

[...] Art. 12 O exercício da docência na Educação Básica, cumprindo o estabelecido nos artigos 12, 13, 61 e 62 da LDB e nas Resoluções N 3/1997 e N² 2/1999, da Câmara da Educação Básica, assim como o parecer do Pleno do Conselho Nacional de Educação, a respeito da formação de professores em nível superior para a Educação Básica, prevê a formação inicial em curso de licenciatura, estabelecendo como qualificação mínima, para a docência na Educação Infantil e nos anos iniciais do Ensino Fundamental, o curso de formação de professores em Nível Médio, na modalidade Normal. (BRASIL, 2002, p. 24)

O Art. $2^{\circ}$ do Parecer da DOEBEC comenta sobre o acesso às modalidades de ensino, enquanto que o Art. 12 alerta para necessidade de 
professoras (es) formadas (os) em licenciaturas, mas não distinguem para necessidade de que tais cursos considerem também temas, conteúdos, metodologias que ouçam os sujeitos que habitam o campo.

Outro dispositivo que anuncia pequenas citações sobre a Educação Infantil é a Resolução CNE/CEB n²/2008, que "Estabelece diretrizes complementares, normas e princípios para o desenvolvimento de políticas públicas de atendimento da Educação Básica do campo". (BRASIL, 2008). A resolução reafirma o Artigo $2^{\circ}$ do Parecer CNE/CEB n.36/2001, corroborando, que as modalidades de ensino serão oferecidas nas próprias comunidades rurais, entretanto deveriam evitar "os processos de nucleação de escolas e de deslocamentos das crianças". (BRASIL, 2008, p.1)

Além disso, a Resolução CNE/CEB n02/2008 no $\S 2^{\circ}$ do Art. 3 destaca que "em nenhuma hipótese serão agrupadas em uma mesma turma crianças de Educação Infantil com crianças do Ensino Fundamental" (BRASIL, 2008, p.2). Apesar de se constituírem em conquistas, não há um maior esclarecimento ou sinalização de alternativas para evitar as práticas de nucleação e/ou deslocamento das crianças, experiências constantes nos territórios rurais do nosso país.

Em 2009, as Diretrizes Nacionais da Educação Infantil (Resolução CNE/CEB n 1/1999 - DCENEI) são revisadas através da Resolução CNE/CEB n $5 / 2009$ e se articulam com as Diretrizes Nacionais da Educação Básica, sendo que a primeira reúne princípios que devem ser analisados a partir de orientações sobre "as políticas públicas na área e a elaboração, planejamento, execução e avaliação de propostas pedagógicas e curriculares" (BRASIL, 2009, p.1) para Educação Infantil em todo o território nacional. Ainda em 2009, incluímos a elaboração de uma Emenda Constitucional, a de № 59 de 11 de novembro de 2009 que prevê a obrigatoriedade do ensino de quatro a dezessete anos, aconselha o atendimento em todas as etapas da educação básica por meio de programas suplementares entre outras mudanças. Essas duas últimas sugerem diretamente sobre a Educação Infantil do Campo quando, se na categoria de opção da família no que tange a matrícula já encontrávamos quadros precários 
no atendimento das crianças, imaginemos quando essa etapa da educação básica se torna obrigatória.

No ano de 2010 podemos apontar dois dispositivos legais que também incidem sobre a Educação Infantil do Campo, entre eles a Resolução No 04/2010 que Define Diretrizes Curriculares Nacionais Gerais para a Educação Básica e Resolução No 06/2010 Diretrizes Operacionais para matrícula no Ensino Fundamental e na Educação Infantil. No capítulo II, Seção IV há um direcionamento específico para a modalidade Educação do Campo, contudo ainda são parcas as considerações acerca desta,

[...] Art. 35. Na modalidade de Educação Básica do Campo, a educação para a população rural está prevista com adequações necessárias às peculiaridades da vida no campo e de cada região, definindo-se orientações para três aspectos essenciais à organização da ação pedagógica: I - conteúdos curriculares e metodologias apropriadas às reais necessidades e interesses dos estudantes da zona rural; II - organização escolar própria, incluindo adequação do calendário escolar às fases do ciclo agrícola e às condições climáticas; III - adequação à natureza do trabalho na zona rural.

[...] Art. 36. A identidade da escola do campo é definida pela vinculação com as questões inerentes à sua realidade, com propostas pedagógicas que contemplam sua diversidade em todos os aspectos, tais como sociais, culturais, políticos, econômicos, de gênero, geração e etnia.

[...] Parágrafo único. Formas de organização e metodologias pertinentes à realidade do campo devem ter acolhidas, como a pedagogia da terra, pela qual se busca um trabalho pedagógico fundamentado no princípio da sustentabilidade, para assegurar a preservação da vida das futuras gerações, e a pedagogia da alternância, na qual o estudante participa, concomitante e alternadamente, de dois ambientes/situações de aprendizagem: o escolar e o laboral, supondo parceria educativa, em que ambas as partes são corresponsáveis pelo aprendizado e pela formação do estudante. (BRASIL, 2010)

Há que se observar que os dispositivos não tocam na especificidade da infância do campo, tão pouco a Seção I do mesmo documento, mesmo tratando da primeira etapa que é a Educação Infantil. Constitui-se em avanço sim, mas tímido, uma vez que é necessário pensarmos que Educação Infantil para as crianças do campo. 
O fato é que o sentido da infância e da Educação Infantil no âmbito rural passa a materializar um objeto de estudo de inegável importância, principalmente pelas lacunas teórico-metodológicas, pela realidade das instituições escolares, de políticas públicas que o tema aponta, que têm desdobramentos incidentes no cotidiano das instituições que atendem a EIC.

\section{Políticas para Educação Infantil do Campo e o cotidiano de instituições escolares: considerações sobre o debate}

A análise empreendida até aqui cumpre uma função de apresentar parte das lutas do povo do campo, dos movimentos sociais e sociedade civil delineada por um ordenamento jurídico que versa sobre a Educação do Campo, de maneira geral, e tem implicações diretas na Educação Infantil do Campo. Mas, para estabelecer uma interface entre o itinerário legislativo e os possíveis desdobramentos no cotidiano das instituições que acolhem crianças de zero a cinco anos, da zona rural é preciso analisar a intensidade do movimento na implementação das políticas.

É importante delimitar que todos os condicionantes dessa implementação estão relacionados à lentidão dos municípios, que de acordo com a lei estão incumbidos de ofertar a Educação infantil. De modo geral legitimam uma organização escolar urbanocêntrica, sem problematizar o calendário e sua adequação aos ciclos agrícolas e às condições climáticas de cada região. Essa constatação denota uma lógica vinculada à economicidade de recursos financeiros, pois com um calendário e horários unificados para todas as crianças matriculadas na rede municipal, implica principalmente no menor investimento nas condições materiais para oferta do ensino neste setor. Atrelados a necessidade de cumprimento deste calendário unificado, definido por iniciativa da gestão municipal, as instituições escolares do campo passam a ter ainda maiores dificuldades em organizar os currículos adequando-os às reais necessidades da vida e do trabalho rural.

Assim, a despeito dos avanços do ordenamento jurídico para a educação do campo é importante frisar que, isso não é sinônimo de garantia de tais direitos. Existe um fosso entre o que preconiza a lei e o que verdadeiramente é 
assegurado ao cidadão. Afinal, os documentos possuem uma linguagem cifrada e pouco discutida por familiares e comunidade no meio rural. Com isso as informações ficam concentradas nos cursos de formação de professores que por sua vez, não alcançam os sujeitos que atuam nas escolas do campo.

Em termos globais, de acordo com Barbosa e Almeida (2019) os cursos de formação de professores historicamente estiveram direcionados ao espaço urbano, com currículos e práticas pedagógicas inspiradas em modelos de vida social, também urbano. Assim, as referências de lutas dos povos das águas, dos campos e dos quilombos estiveram esquecidas nestes cursos. Esse fator dificulta a inserção e envolvimento dos profissionais da educação para atuarem de maneira vibrante junto à escola, à família, à comunidade e principalmente intervir na gestão municipal em defesa do processo de democratização da educação considerando as necessidades deste setor.

Ao trazer à baila, que apenas recentemente os profissionais da educação passaram a ter momentos específicos para discutir sobre a legislação que permeia a Educação do Campo, implica dizer que se faz necessário um investimento em formação continuada que paute o referido tema.

No caminho que vem sendo percorrido, para discutir as políticas instituídas e os desdobramentos nas instituições escolares, a formação dos profissionais da educação é, por excelência, um passo importante das políticas. Para além da atenção ao itinerário legislativo implica compreender o processo de invisibilidade das crianças do campo e como os avanços no marco legal se constituem em elementos importantes de luta pela garantia de uma educação de qualidade para as crianças do território rural.

A formação de professores, por exemplo, precisa implicá-los de forma que empreendam um olhar sobre sua prática assumindo a EC como um espaço de democratização da sociedade brasileira e de inclusão social. Compreende-se então, o campo com suas histórias e direitos, e os alunos enquanto sujeitos sociais, culturais, éticos e políticos (ARROYO; CALDART; MOLINA; 2008).

Para tanto, essa formação precisa ser desenhada preferencialmente como uma política pública de duração constante para debater e consolidar documentos que orientem o currículo, projetos políticos pedagógicos, entre 
outros elementos imprescindíveis para EIC. Nesse meandro cabe a luta pela valorização dos profissionais, por melhores condições de trabalho nas escolas do campo e por infraestrutura adequada para as instituições como preconizadas nos documentos analisados.

A partir da análise do itinerário legislativo voltados para as questões da Educação do Campo e Educação Infantil do Campo, nota-se que houve um avanço do ponto de vista da legislação com relação ao atendimento. Contudo, ainda não é satisfatória para acolher todas as crianças que têm o direito ingressar e permanecer na instituição de EIC de qualidade. A luta contra as condições de exclusão e desigualdade que esses sujeitos vivenciam é contínua, não deve cessar. A defesa aqui é que as políticas públicas sejam criadas e implementadas com a intenção de contribuir para a melhoria das condições de vida das infâncias do campo, historicamente invisibilizadas. Assim, as crianças do campo, além de terem direito ao processo de desenvolvimento $\mathrm{e}$ aprendizagem conforme estabelece a legislação, precisam ter garantias e condições de acesso e permanência.

Conhecer e entender quem são as crianças que povoam o campo se constitui em um desafio para pensarmos e construirmos uma Educação Infantil que atenda as demandas das crianças ribeirinhas, caiçaras, quilombolas, das florestas e assentadas. Lutar por políticas de educação que assegurem e respeitem as crianças que povoam o campo, bem como a pluralidade os diferentes contextos familiares das crianças reconhecendo as suas particularidades têm sido e será um grande desafio e que precisa se assentar nas agendas nacionais.

Apesar dos avanços, há muito que se fazer e lutar pelo ingresso e permanência das crianças desde a primeira infância no universo escolar da zona rural. Pensar e construir alternativas diante do que for peculiar em cada território rural do país, considerando manifestações e artefatos culturais, características geográficas, econômicas, ambientais, populacionais, o que implicará também no cotidiano das instituições escolares que atendem as crianças da EIC. Sendo crianças, possuem especificidades, vivem realidades distintas em tais espaços, 
em meio as suas famílias que possuem conformações diferentes em diversos âmbitos.

Pensar as políticas para a Educação Infantil no e do Campo nos conduz a reflexão sobre contrassensos existentes nos sistemas de educação ao não consolidar suas responsabilidades junto às as crianças da zona rural. Existe um fosso entre o que preconizam os dispositivos legais e o que de fato se efetiva em tais espaços. Nesse sentido, as políticas de Educação Infantil voltadas para os cotidianos rurais indicam a necessidade de considerar a perspectiva sociocultural da infância no rural: os modos de vida, produção e significado da educação para seus sujeitos e suas instituições.

Educação Infantil do Campo, carece de pesquisas e ações voltadas para mesma, analisando que estão enredadas visões de infância, criança, Educação do Campo e Educação Infantil que provocam a necessidade de compreender sua complexidade e peculiaridades. A EIC se compõe como um lugar essencial e imperativo para o desenvolvimento integral das crianças.

As políticas públicas para EC e EIC são condições indispensáveis para garantia de manutenção de direitos já adquiridos e para reivindicação de outros tantos que abarquem a qualidade de vida dos sujeitos do campo.

\section{Considerações Finais}

O presente artigo analisou o processo de implementação das políticas na Educação Infantil do Campo e os possíveis desdobramentos no cotidiano das instituições. Considera-se que houve avanços no que diz respeito a implementação de políticas para a EC, porém ainda será necessário desenvolver ações que alcancem de maneira direcionada as crianças dos territórios rurais considerando suas necessidades e especificidades.

Percebe-se um ritmo ainda lento e, esse mesmo ritmo, implica os possíveis desdobramentos nas instituições. Destarte, no cotidiano das instituições, efetivamente ainda não há desdobramentos consubstanciados, em direção à consolidação de Educação Infantil do Campo à luz dos avanços propostos pelo ordenamento jurídico. 
A análise empreendida sobre o itinerário legislativo até aqui, indica que a dinâmica organizacional das escolas do campo, bem como o trabalho pedagógico realizado nas mesmas, necessita muito mais que a participação efetiva dos profissionais das instituições, que já buscam contribuir com a realidade que atuam. Faz-se necessário elaboração e acompanhamento de políticas públicas que garantam formação inicial e continuada de professores; melhores condições de trabalho; espaços físicos condizentes com as necessidades e realidades de cada localidade; materiais didáticos, calendários e projetos políticos pedagógicos direcionados as experiências de cada realidade, entre outras garantias, como tentativa de romper com o modelo de educação predominante, de políticas que não contemplam os povos do campo e nem às especificidades do contexto sociocultural da Educação Infantil do Campo.

\section{Referências}

ARROYO, Miguel Gonzalez; CALDART, Roseli S.; MOLINA, Mônica Castagna (Org.). Por uma educação do campo. 3. Ed. - Petrópolis, RJ: Vozes, 2008.

BARBOSA, Maria Carmen S.; GEHLEN, Ivaldo; FERNANDES, Susana Beatriz. A Oferta e demanda de educação infantil no campo: um estudo a partir de dados primários. In: BARBOSA, Maria Carmen Silveira et al. (coordenadoras). Oferta e demanda de educação infantil no campo. Porto Alegre: Evangraf, 2012. p. 73105.

BARBOSA, Elizabete Pereira. A Fábrica, a Casa e a Escola: As Políticas de Educação para a Infância no Recôncavo Fumageiro da Bahia (1925 -1946). Tese (Doutorado em Educação) - Universidade Federal da Bahia. Salvador, p. 228. 2015. Disponível em: https://repositorio.ufba.br/ri/handle/ri/18531. Acesso em: 16 de junho de 2020.

BARBOSA, Elizabete Pereira; ALMEIDA, Luciana Freitas de Oliveira. O trabalho pedagógico com jogos e brincadeiras na educação infantil do Campo. In: SOUSA, Ivan Vale de (org.) Letras, Linguística e Artes: Perspectivas Críticas e Teóricas; v. 2; [recurso eletrônico]. Ponta Grossa (PR): Atena Editora, 2019.

BRASIL. Constituição da República Federativa do Brasil de 1988. Brasília, DF: Senado Federal, 1988.

. Lei n. 8.069, de 13 de julho de 1990. Estabelece o Estatuto da criança e do adolescente. 3. ed. Brasília. 
Lei n. 9.394 de 20 de dezembro de 1996. Estabelece as Diretrizes

e Bases da Educação. Disponível em:

http://www.planalto.gov.br/ccivil 03/leis/L9394.htm Acesso em: 29. mar.2017

Referencial Curricular Nacional para a Educação Infantil / Ministério da Educação e do Desporto, Secretaria de Educação Fundamental. Brasília: MEC/SEF, 1998.

Ministério da Educação. Secretaria de Educação Básica. Resolução $\overline{\mathrm{CNE} / \mathrm{CEB}} \mathrm{n}^{01 / 2002}$ que designa as Diretrizes Operacionais para Educação Básica nas Escolas do Campo. Brasília: MEC, SEB, DF: 2002

Ministério da Educação. Secretaria de Educação Básica. Parâmetros nacionais de qualidade para a educação infantil. - Brasília: MEC, SEB, DF. 2006 (v.1 e v.2)

. Ministério da Educação. Secretaria de Educação Básica. Parâmetros básicos de infraestrutura para instituições de educação infantil. Brasília: MEC, SEB, 2006a.

Parecer CNE/CEB 1/200627 que aborda sobre Dias letivos para a aplicação da Pedagogia de Alternância nos Centros Familiares de Formação por Alternância (CEFFA). Secretaria de Educação Continuada, Alfabetização e Diversidade - SECAD/MEC, Brasília, 2006b.

Parecer CNE/CEB 23/2007 relativo à Consulta referente às Orientações para o Atendimento da Educação do Campo. Ministério da Educação/Secretaria de Educação Continuada, Alfabetização e Diversidade SECAD. Brasília, 2007.

. Ministério da Educação. Conselho Nacional de Educação. Câmara de Educação Básica. Resolução n.2, de 28 de abril de 2008 que estabelece Diretrizes Complementares, Normas e Princípios para o Desenvolvimento de Políticas de Atendimento da Educação Básica no Campo. Brasília: MEC, SEB, DF: 2008.

. MEC/CNE/CEB. Resolução No 5, de 17 de dezembro de 2009. Institui Diretrizes Curriculares Nacionais para a Educação Infantil. Disponível em: http://portal.mec.gov.br/cne/ index//.pdf12992:diretrizeparaeducaçãobasica: Acesso em: 10/03/2017.

. Ministério da Educação. Secretaria de Educação Básica. Emenda Constitucional n$^{\circ} 59$ de 11 de novembro de 2009 que dá nova redação aos incisos I e VII do art. 208, de forma a prever a obrigatoriedade do ensino de quatro a dezessete anos. Básica. Brasília: MEC, SEB, DF: 2009.

Ministério da Educação. Nota técnica sobre I Seminário Nacional da Educação Infantil do campo. Sistematização dos encaminhamentos. Brasília: 257 MEC, SEB, DF: 2010. 
CALDART, Roseli Salete. Educação do campo: notas para uma análise do percurso. In. Revista Trabalho Educação e saúde. Rio de janeiro, v.7, n.1, PP 35-64, mar/jun de 2009.

Dicionário da Educação do Campo. Rio de Janeiro, São Paulo: Escola Politécnica de Saúde Joaquim Venâncio, Expressão Popular, 2012.

CAVALCANTE, Ludmila Oliveira Holanda. A escola família Agrícola do Sertão: entre os percursos sociais, trajetórias pessoais e implicações ambientais. Tese de Doutorado em Educação, Universidade Federal da Bahia, Salvador/Bahia, 2007.

- Das políticas ao cotidiano: entraves e possibilidades para educação do campo alcançar as escolas no rural. Ensaio: Avaliação e Políticas Públicas em Educação, Rio de Janeiro, v. 18, n. 68, p. 549-564, jul./set. 2010

UZÊDA, Leomárcia C. de Oliveira; REHEM, Fani Quitéria N;

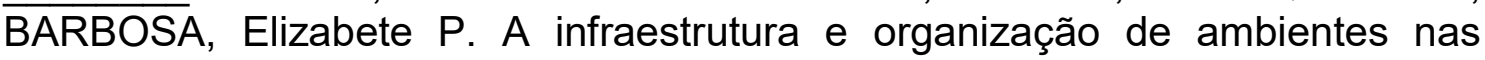
instituições de educação infantil do campo: desafios e possibilidades. Anais IV Seminário de Grupos de Pesquisa sobre Crianças e Infâncias (GRUPECI). Goiânia, GO: Universidade Federal de Goiás,2014.

KRAMER, Sonia e LEITE Maria Isabel (Orgs.). Infância: Fios e Desafios da Pesquisa. 8. ed. Campinas, São Paulo: Papirus, 1996.

KUHLMANN Jr, Moysés. Histórias da Educação Infantil Brasileira. Revista Brasileira de Educação. n. 14, Mai/Jun/Jul/Ago, 2000, № 14.

LAJOLO, M. (1997). Infância de Papel e Tinta. In: FREITAS, M. C. História Social da Infância no Brasil. 2. ed. São Paulo: Cortez, 2009, p. 229-251.

MUNARIM, A. Movimento nacional de educação do campo: uma trajetória em construção. Anais da XXXI Reunião Anual da Anped. GT 03: Movimentos Sociais e Educação. Caxambu, MG, 2008.

SILVA, A. P. S.; PASUCH, J. Orientações Curriculares Nacionais para a Educação Infantil do Campo. In: I Seminário Nacional: Currículo em Movimento - Perspectivas Atuais, Belo Horizonte, 2010.

SILVA, A. P. S.; PASUCH, J.; SILVA, J. B. Educação Infantil do campo. São Paulo: Cortez, 2012.

SOUZA, Maria Antônia de. Educação do campo: políticas, práticas pedagógicas e produção científica. Educação e Sociedade. Campinas, vol. 29, n. 105, set./dez. 2008, p. 1096.

UZÊDA, Leomárcia Caffé de Oliveira. "O que você descobriu sobre a gente?" A escola de Educação Infantil do Campo a partir do olhar das crianças. 276f. Tese (Doutorado) - Faculdade de Educação, Universidade Federal da Bahia, Salvador, 2013.

Disponível

em: 
https://repositorio.ufba.br/ri/bitstream/ri/23970/1/TESE VERS\%C3\%830\%20D EP\%C3\%93SITO EIC LCOU.pdf .

\section{Sobre as autoras}

\section{Leomárcia Caffé de Oliveira Uzêda}

leomarciauzeda@uefs.br

Possui doutorado em Educação pela Universidade Federal da Bahia, mestrado em Educação e Contemporaneidade pela Universidade do Estado da Bahia/UNEB, especialização em Supervisão Escolar pela Universidade Estadual de Feira de Santana (UEFS/BA), graduação em Licenciatura em Pedagogia pela Universidade Federal da Bahia (UFBA). Atualmente é professora Adjunta da Universidade Estadual de Feira de Santana (UEFS), Vice-coordenadora do Centro de Estudos e de Documentação em Educação (CEDE-UEFS) e Coordenadora do Programa de Extensão Brinquedoteca UEFS. ORCID: https://orcid.org/0000-0002-0690-5340. Endereço para acessar este CV: http://lattes.cnpq.br/8304862148746207

\section{Elizabete Pereira Barbosa.}

beteuefs@uefs.br

Possui doutorado em Educação pela Universidade Federal da Bahia (UFBA2015), mestrado em Ciências Agrárias pela Universidade Federal da Bahia (UFBA-2004), especialização em Supervisão Escolar pela Universidade Estadual de Feira de Santana (UEFS-1999), graduação em Pedagogia pela Universidade Estadual de Feira de Santana (UEFS-1997). Atualmente é Professora Adjunta da Universidade Estadual de Feira de Santana (UEFS) e Coordenadora do Centro de Estudos e de Documentação em Educação (CEDE-UEFS). ORCID: https://orcid.org/0000-0002-0512-4374. Endereço para acessar este CV: http://lattes.cnpq.br/1087256408138623. 